\title{
Temas y actores frente al Chikungunya en medios de la prensa escrita de Paraguay
}

\author{
Patricia Lima Pereira \\ Asesora en Planificación y Comunicación. \\ Dirección General de Vigilancia de la Salud. Ministerio de Salud Pública y Bienestar Social. \\ Paraguay \\ Zaida Meza \\ Dirección General de Comunicación en Salud, Ministerio de Salud Pública y Bienestar Social, \\ Paraguay \\ Fátima Santander \\ Dirección General de Comunicación en Salud, Ministerio de Salud Pública y Bienestar Social, \\ Paraguay \\ Lus Ferreira \\ Dirección General de Comunicación en Salud, Ministerio de Salud Pública y Bienestar Social, \\ Paraguay
}

\section{Palabras clave \\ Planes de Contingencia \\ Virus Chikungunya \\ Prensa \\ Comunicación de Riesgo \\ Percepción de Riesgo}

\section{Resumen}

El virus Chikungunya es transmitido por mosquitos Aedes aegypti y el Aedes albopictus y produce una enfermedad febril aguda con dolor articular. El primer caso autóctono se detectó en América en diciembre de 2013. En junio de 2014, el Ministerio de Salud elaboró un plan de contingencia, que incluía la Comunicación de Riesgo. El objetivo de este estudio fue describir los temas y actores relevantes en medios de prensa, evaluar los resultados de la capacitación a periodistas y analizar cómo la información proveída por la vocería pública fue replicada en los medios privados. Se realizó el análisis de contenido de publicaciones en medios de prensa escrita de Paraguay de junio a octubre de 2014. Se calculó la frecuencia de las variables y se compararon grupos, incluyendo pruebas de significancia, con el software Epi Info 7. De 142 publicaciones analizadas, 76 (53,5\%) correspondieron al sector privado y $66(46,5 \%)$ al público. El $60 \%$ tuvo como contenido central: el anuncio de casos (18,3\%), las medidas de control vectorial $(17,6 \%)$, la alerta (12\%) o el plan de contingencia $(11,3 \%)$. Un $18,4 \%$ de las noticias de prensa reprodujeron la información del sector público de manera textual y 27,6\% lo hicieron parcialmente. Los temas fueron más frecuentemente replicados por los medios fueron el "Número de casos" (razón=2,6) y las "Alertas" (razón=2,3). Menor replicabilidad tuvo la información sobre "Plan" y "Medidas de prevención ambiental". Se concluye que proveer información a la prensa es una acción eficaz dentro de un plan de comunicación de riesgo, pero es necesario identificar temas claves. Las publicaciones oficiales que insisten en mensajes de prevención y temas sobre planificación no son siempre replicadas textualmente en los medios, pero mantienen un aceptable nivel de replicabilidad y ayudan a mantener la confianza en las fuentes oficiales.

Autor para correspondencia: Patricia Lima Pereira: Dirección General de la Vigilancia de Salud. Ministerio de Salud Pública. Paraguay. Correo electrónico: patricialimap@gmail.com 


\section{Topics and actors against the Chikungunya in the press media of Paraguay}

\author{
Keywords \\ Contingency plans \\ Chikungunya virus \\ Mass Media \\ Risk Communication \\ Risk perception
}

\begin{abstract}
Chikungunya is a mosquito-borne viral disease that causes fever and severe joint pain. The first documented outbreak of chikungunya with autochthonous transmission in the Americas started in December 2013. By June 2014, many countries in the Americas, including Paraguay, developed Risk Communication plans. The aim of this study was to describe the issues and the actors in the media, evaluate the results of training journalists and analyze how the information provided by the public sector was replicated in the private media. Content analysis of publications in print media of Paraguay from June to October 2014 was conducted. The frequency of variables was calculated, including significance test, using Epi Info 7. Of 142 articles reviewed, 76 (53.5\%) corresponded to the private sector and 66 (46.5\%) to the public. The $60 \%$ had as its content: the announcement of cases (18.3\%), vector control measures (17.6\%) and warnings (12\%). Significant difference was found in the selection of the main topics depending on whether the media belonged to the public or private sector. $80.8 \%$ of the news that had as its central focus "announcement of new cases" were for private media $(p=0.004)$ and $87.5 \%$ of which had as its central focus the existence of a plan contingency corresponded to the public sector $(p=0.001)$. Also, the news that highlighted training topics were published in $83.3 \%$ in the public media sector ( $p=0.017$ ). The $18.4 \%$ of news reproduced textually the public information and $27.6 \%$ did so partially. The topics most frequently replicated by the media were the "Number of cases" (replicability ratio=2.6) and the "Alerts" (replicability ratio=2.3). As conclusion, providing information to the press is an effective action within a risk communication plan. Public publications that insisted with prevention messages and planning issues are not been reported verbatim in the media, but maintained an acceptable degree of replicability, which reflected reliance on official sources.
\end{abstract}

\section{Cómo citar el artículo}

Lima Pereira, P.; Meza, Z.; Santander, F., y Ferrerira, L. (2015). Temas y actores frente al Chikungunya en medios de la prensa escrita de Paraguay. Revista de Comunicación y Salud, Vol. 5, pp. 17-36.

DOI: http://doi.org/10.35669/revistadecomunicacionysalud.2015.5.17-36 


\section{Introducción}

El virus Chikungunya es transmitido por los mosquitos Aedes aegypti y el Aedes albopictus y produce una enfermedad febril aguda con dolor articular. El primer caso autóctono se detectó en América en diciembre de 2013. Hasta la semana epidemiológica 44 de 2014 se habían reportado 780.206 casos autóctonos sospechosos y fueron confirmados 13.357 casos autóctonos y 1.885 importados (2 en Paraguay) (OPS, 2014).

En junio de 2014, el Ministerio de Salud elaboró un "Plan Nacional ante el Riesgo de Introducción de Chikungunya en Paraguay 2014", que incluía como componente la Comunicación de Riesgo (MSPBS, 2014).

El Plan de Comunicación de Riesgo resultante determinó como objetivo principal aumentar el involucramiento informado de la población, los líderes de opinión y del personal de salud en las acciones de contingencia frente a una epidemia de Chikungunya (CHIK). Una de las metas esperadas fue que el $100 \%$ de los medios de comunicaciones nacionales y regionales presenten información ecuánime, alineada a las acciones del plan de prevención y contingencia.

Como acciones prioritarias en la fase de preparación relacionadas con los medios de prensa se definió la necesidad de realizar un taller de capacitación y planificación conjunta de los equipos regionales y locales de Promoción y Comunicación, realizar un taller de entrenamiento a voceros institucionales a nivel nacional y regional, mantener activo contacto con referentes de medios de comunicación públicos y privados y formadores de opinión de nivel nacional y regional, el diseño, elaboración y validación de una campaña de comunicación sobre CHIK.

Se estableció que la capacitación específica para periodistas sería uno de los medios para establecer contacto con este público, además de gacetillas, comunicados, correos electrónicos, llamadas y mensajes por teléfono, Whatsapp y otras redes sociales, sitio web, conferencias de prensa y entrevistas pautadas.

Los mensajes claves definidos para la fase de preparación fueron: "Existe un plan", "Somos transparentes: damos información actualizada, organizada", "EI mosquito es el vector", "Impacto social y económico", "Diferencias con el dengue", "Signos y síntomas", "Medidas de protección personal y social" y "Explicación de cómo ingresaría el virus al territorio".

Se realizaron en total 9 talleres de capacitación a periodistas y comunicadores. El taller dirigido a periodistas del sector privado de Asunción se realizó el 11 de julio de 2014. Participaron en total de los talleres, 269 personas, entre periodistas de medios de prensa privados, de medios de prensa del sector público, comunicadores institucionales y profesionales de salud de servicios públicos. 


\section{Objetivos}

El objetivo del estudio es describir los temas y actores relevantes relacionados al Chikungunya aparecidos en medios de prensa en Paraguay, correspondiente a la primera fase del plan de preparación, entre junio a octubre de 2014 y evaluar los resultados del taller de capacitación dirigido a periodistas y analizar cómo la información proveída por la vocería pública es replicada en los medios de prensa privados.

\section{Métodos}

Se trata de un estudio descriptivo retrospectivo y análisis de contenido de publicaciones en medios de prensa escrita de Paraguay durante el período de junio a octubre de 2014.

Se identificaron cuatro medios de prensa escrita de Paraguay privados, cuyas publicaciones tanto su versión impresa como digital estuvieran disponibles en la web. Entre los medios privados se incluyeron los diarios ABC, Hoy, La Nación y Última Hora, (en su versión impresa y digital). Además se seleccionaron dos medios de información del sector público: el boletín de noticias del Ministerio de Salud Pública y Bienestar Social y la Agencia de Información Paraguaya (IP), ambos disponibles en sitios de internet y el primero, remitido sistemáticamente a los periodistas a través de correo electrónico y redes sociales.

A través del monitoreo de prensa sistemático instalado en la Dirección General de Comunicación en Salud del Ministerio de Salud Pública y Bienestar Social, fueron identificadas e incluidas en el estudio todas las publicaciones de los medios citados aparecidas durante el período de 1 de junio al 30 de octubre de 2014 y que incluían al menos una mención al virus o la enfermedad producida por el virus de Chikungunya.

Las publicaciones identificadas fueron impresas y cargadas en una base de datos los valores de: fecha de publicación, medio de publicación, tipo (público o privado), tema central, temas secundarios, la extensión de la noticia (en párrafos), extensión y actores citados.

El tema central de la noticia se determinó a través de un análisis de contenido a partir del título de la publicación o cuando éste era muy genérico (por ejemplo, se titulaba sólo "Chikungunya"), según la información del primer párrafo. Se identificó además el tema central de cada párrafo y estos fueron clasificados como temas secundarios.

Los temas centrales fueron agrupados en 15 temas y los temas secundarios en un total de 18 temas. Se contabilizó la frecuencia de cada tema central (uno por cada publicación) y de los temas secundarios (más de uno por cada publicación, según mención en el texto analizado). Se identificaron además los actores citados en cada noticia.

A modo de triangulación, la clasificación de los temas fue revisada en dos días diferentes por el mismo investigador, para la probar la concordancia con la clasificación. 
Se calculó la frecuencia de las variables y se compararon grupos, incluyendo pruebas de significancia cuando aplicaba (Chi-cuadrada corregida Yates).

Para el análisis de los datos se utilizó el software Epi Info 7.

\section{Resultados}

De analizaron en total 142 publicaciones, de las cuales 76 publicaciones $(53,5 \%)$ correspondieron al sector privado y 66 (46,5\%) al sector público.

El $59,2 \%$ de las publicaciones analizadas tuvo como contenido central alguno de los siguientes cuatro temas: a. El anuncio de nuevos casos $(18,3)$, b. las medidas de control ambiental y/o vectorial $(17,6 \%)$, c. la alerta (12) y d. información sobre el plan y/o los protocolos de contingencia (11,3\%). Tabla 1.

\section{Tabla 1. Temas centrales de las publicaciones}

$\mathrm{N}=142$

\begin{tabular}{llllll}
\hline Tema central de la noticia & $\mathbf{n}$ & $\%$ & \multicolumn{2}{l}{$\begin{array}{l}\text { Porcentaje } \\
\text { acumulado }\end{array}$} \\
\hline Número de casos - Anuncio & de & & & & \\
caso & 26 & 18,3 & 18,3 & $(12,3-25,7)$ \\
Medidas de prevención ambiental & 25 & 17,6 & 35,9 & $(11,7-24,9)$ \\
Alerta & 17 & 12,0 & 47,9 & $(7,1-$ & $18,5)$ \\
Plan - protocolos & 16 & 11,3 & 59,2 & $(6,6-$ & $17,7)$ \\
Capacitación & 12 & 8,5 & 67,6 & $(4,4-$ & $14,3)$ \\
Diagnóstico - Tratamiento & 8 & 5,6 & 73,2 & $(2,5-$ & $10,8)$ \\
Medidas de protección personal & 7 & 4,9 & 78,2 & $(2,0-$ & $9,9)$ \\
Mosquito - Criaderos & 7 & 4,9 & 83,1 & $(2,0-$ & $9,9)$ \\
Síntomas & 7 & 4,9 & 88,0 & $(2,0-$ & $9,9)$ \\
Similitud con el dengue & 6 & 4,2 & 92,3 & $(1,6-$ & $9,0)$ \\
Autorreporte y/o consulta médica & 3 & 2,1 & 94,4 & $(0,4-$ & $6,1)$ \\
Intersectorialidad & 3 & 2,1 & 96,5 & $(0,4-$ & $6,1)$ \\
Historia de la enfermedad & 2 & 1,4 & 97,9 & $(0,2-$ & $5,0)$ \\
Susceptibilidad - Riesgo & 2 & 1,4 & 99,3 & $(0,2-$ & $5,0)$ \\
Origen de la palabra & 1 & 0,7 & 100 & $(0,0-$ & $3,9)$ \\
\hline Total & $\mathbf{1 4 2}$ & $\mathbf{1 0 0}$ & & & \\
\hline
\end{tabular}


Se encontró diferencia en la selección de los temas centrales según el sector al que pertenecía el medio. Las noticias que tenían como eje central el "anuncio de nuevos casos" correspondieron en un $80,8 \%$ a medios de comunicación privados $(p=0,004)$ y las que tenían como foco central la existencia de un plan de contingencia correspondieron en un $87,5 \%$ al sector público $(p=0,001)$. Asimismo, las noticias que resaltaban la capacitación realizada en el marco de la contingencia al Chikungunya se publicaron en un $83,3 \%(p=0,017)$ en medios de comunicación del sector público. Tabla 2.

Tabla 2. Tema principal de la noticia, según sector al que pertenece el medio de comunicación

\begin{tabular}{llllllll} 
& \multicolumn{1}{c}{ Sector del medio de comunicación } & \multicolumn{2}{l}{ m=142 } \\
Tema principal de la publicación & \multicolumn{2}{c}{ Privado } & $\%$ & Público & $\%$ & TOTAL & p \\
\hline Número de casos - Anuncio caso* & 21 & 80,8 & 5 & 19,2 & 26 & 0,004 \\
Medidas de prevención & 10 & 40,0 & 15 & 60,0 & 25 & \\
ambiental & 13 & 76,5 & 4 & 23,5 & 17 & \\
Alerta & 2 & 12,5 & 14 & 87,5 & 16 & 0,001 \\
Plan - protocolos* & 2 & 16,7 & 10 & 83,3 & 12 & 0,017 \\
Capacitación* & 4 & 50,0 & 4 & 50,0 & 8 & \\
Diagnostico - Tratamiento & 4 & 57,1 & 3 & 42,9 & 7 & \\
Medidas de protección persona & 3 & 42,9 & 4 & 57,1 & 7 & \\
Mosquito - Criaderos & 6 & 85,7 & 1 & 14,3 & 7 & \\
Síntomas & 5 & 83,3 & 1 & 16,7 & 6 & \\
Similitud con el dengue & 1 & 33,3 & 2 & 66,7 & 3 & \\
Autorreporte y/o consulta médica & 0 & 0 & 3 & 100 & 3 & \\
Intersectorialidad & 2 & 100 & 0 & 0 & 2 & \\
Historia de la enfermedad & 2 & 100 & 0 & 0 & 2 & \\
Susceptibilidad - Riesgo & 1 & 100 & 0 & 0 & 1 & \\
Origen de la palabra & $\mathbf{7 6}$ & $\mathbf{5 3 , 5}$ & $\mathbf{6 6}$ & $\mathbf{4 6 , 5}$ & $\mathbf{1 4 2}$ & \\
\hline Total & & & & &
\end{tabular}

En relación al análisis de los subtemas contenidos en las noticias, se verificó que el $51,4 \%$ las publicaciones hacían mención al plan o protocolos de la contingencia. Esta mención fue un $63,6 \%$ en las publicaciones del sector público y se dio en un 40,8 \% de las publicaciones del sector privado. Tabla 3.

Tabla 3. Temas en general abordados en las publicaciones

\begin{tabular}{lllll}
\hline Total de temas incluidos & n & \% & \multicolumn{3}{c}{ IC95\% } \\
\hline Plan - protocolos & 73 & 51,4 & 42,9 & 59,9 \\
Mosquito - Criaderos & 62 & 43,7 & 35,4 & 52,2 \\
Número de casos - Anuncio de caso & 58 & 40,9 & 32,7 & 49,4 \\
Síntomas & 57 & 40,1 & 32,0 & 48,7 \\
Medidas de prevención ambiental & 56 & 39,4 & 31,4 & 48,0 \\
Ubicación de los casos & 55 & 38,7 & 30,7 & 47,3 \\
Similitud con el dengue & 44 & 30,9 & 23,5 & 39,3
\end{tabular}


Susceptibilidad - Riesgo

Diagnostico - Tratamiento

Antecedente de viaje

Intersectorialidad

Autorreporte y/o consulta médica

Alerta

Medidas de protección persona

Capacitación

Origen de la palabra

Links de consulta web y/o teléfonos

Historia de la enfermedad
43

39

38

36

35

30

26

22

14

12

8
30,3

27,5

26,8

25,3

24,7

21,1

18,3

15,5

9,9

8,5

5,6
22,9

20,3

19,7

18,4

17,8

14,7

12,3

10,0

5,5

4,4

2,5
38,6

35,6

34,9

33,3

32,6

28,8

25,7

22,5

16,0

14,3

10,8

La preocupación por la permanencia de criaderos con mosquitos fue mencionado en el $43,7 \%$ de las publicaciones (sin diferencia para los sectores públicos y privados), mientras que el $40,9 \%$ de las noticias se refería al "número de casos", incluyendo el "anuncio de nuevos casos confirmados o sospechosos". Esta mención se dio en un 55,3\% en los medios del sector privado y un $24,4 \%$ en el sector público. Tabla 4.

Tabla 4. Total de temas abordados en las publicaciones, según sector público o privado al que pertenece el medio de comunicación

\begin{tabular}{llllll}
\hline & \multicolumn{2}{l}{$\begin{array}{l}\text { Sector } \\
\text { público }\end{array}$} & \multicolumn{2}{l}{$\begin{array}{l}\text { Sector } \\
\text { privado }\end{array}$} & N=142 \\
\cline { 2 - 6 } Total de temas incluidos & $\mathbf{n}$ & $\mathbf{\%}$ & $\mathbf{n}$ & $\mathbf{\%}$ & $\boldsymbol{p}$ \\
\hline Plan - protocolos* & 42 & 63,6 & 31 & 40,8 & $0,01^{*}$ \\
Mosquito - Criaderos & 29 & 43,9 & 33 & 43,4 & 0,91 \\
Número de casos - Anuncio de caso* & 16 & 24,4 & 42 & 55,3 & $<0,001^{*}$ \\
Síntomas & 20 & 30,3 & 37 & 48,7 & 0,51 \\
Medidas de prevención ambiental & 29 & 43,9 & 27 & 35,5 & 0,29 \\
Ubicación de los casos & 22 & 33,3 & 33 & 43,4 & 0,28 \\
Similitud con el dengue & 17 & 25,8 & 27 & 35,6 & 0,28 \\
Susceptibilidad - Riesgo & 18 & 27,3 & 25 & 32,9 & 0,59 \\
Diagnostico - Tratamiento & 16 & 24,4 & 23 & 30,3 & 0,54 \\
Antecedente de viaje & 10 & 15,5 & 28 & 36,8 & $0,006^{*}$ \\
Intersectorialidad & 22 & 33,3 & 14 & 18,4 & 0,09 \\
Autorreporte consulta médica & 21 & 31,8 & 14 & 18,4 & 0,31 \\
Alerta & 11 & 16,7 & 19 & 25,0 & 0,31 \\
Medidas de protección persona & 12 & 18,2 & 14 & 18,4 & 0,86 \\
Capacitación & 18 & 27,3 & 4 & 5,3 & $<0,001^{*}$ \\
Origen de la palabra* & 2 & 3,0 & 12 & 15,8 & $0,02^{*}$ \\
Links de consulta web y/o teléfonos & 9 & 13,6 & 3 & 4,0 & 0,08 \\
Historia de la enfermedad & 1 & 1,5 & 7 & 9,2 & 0,11 \\
\hline
\end{tabular}

Los actores citados con mayor frecuencia en las publicaciones tanto del sector privado como público fueron el Ministerio de Salud Pública y la Dirección General de Vigilancia de la Salud. En tercer lugar de mención se identificó a la 
ciudadanía como un actor clave (llamada en algunas publicaciones "comunidad" y en otras "población"). Tabla 5.

\section{Tabla 5. Actores citados en las publicaciones, según sector público o privado al que pertenece el medio de comunicación}

\begin{tabular}{|c|c|c|c|c|c|c|c|c|c|c|c|c|}
\hline \multirow[b]{2}{*}{$\begin{array}{l}\text { Actores citados en las } \\
\text { publicaciones }\end{array}$} & \multicolumn{4}{|c|}{ Sector público } & \multicolumn{4}{|c|}{ Sector privado } & \multicolumn{4}{|c|}{ Total } \\
\hline & $\mathbf{n}$ & $\%$ & & $\begin{array}{l}\text { IC95 } \\
\%\end{array}$ & $\mathbf{n}$ & $\%$ & & $\begin{array}{l}\text { IC95 } \\
\%\end{array}$ & $\mathbf{n}$ & $\%$ & & $\begin{array}{l}\text { IC95 } \\
\%\end{array}$ \\
\hline Ministerio de Salud & 38 & 57,6 & 44,8 & 69,7 & 42 & 55,3 & 43,3 & 66,7 & 80 & 56,3 & 47,8 & 24,9 \\
\hline $\begin{array}{l}\text { Dirección General de Vigilancia } \\
\text { de la Salud } \\
\text { Comunidad y/o Ciudadanía v/o }\end{array}$ & 33 & 50,0 & 37,4 & 62,6 & 31 & 40,8 & 29,7 & 52,7 & 64 & 45,1 & 36,7 & 53,6 \\
\hline $\begin{array}{l}\text { Población } \\
\text { Servicios de Salud (Regiones } \\
\text { Sanitarias, Hospitales públicos, }\end{array}$ & 18 & 27,3 & 17,0 & 39,6 & 23 & 30,3 & 20,3 & 41,9 & 41 & 28,9 & 21,6 & 37,1 \\
\hline USF) & 19 & 28,8 & 18,3 & 41,3 & 13 & 17,1 & 9,4 & 27,5 & 32 & 22,5 & 16,0 & 30,3 \\
\hline OPS/OMS & 8 & 12,1 & 5,4 & 22,5 & 17 & 22,4 & 13,6 & 33,4 & 25 & 17,6 & 11,7 & 24,9 \\
\hline $\begin{array}{l}\text { SENEPA } \\
\text { Laboratorio Central de Salud }\end{array}$ & 12 & 19,2 & 9,8 & 29,6 & 13 & 17,1 & 9,4 & 27,5 & 25 & 17,6 & 11,7 & 24,9 \\
\hline $\begin{array}{l}\text { Pública } \\
\text { Medios de Comunicación y/o }\end{array}$ & 9 & 13,6 & 6,4 & 24,3 & 15 & 19,7 & 11,5 & 30,5 & 24 & 16,9 & 11,1 & 24,1 \\
\hline $\begin{array}{l}\text { Periodistas } \\
\text { Municipalidades }\end{array}$ & 7 & 10,6 & 4,4 & 20,6 & 9 & 11,8 & 5,6 & 21,3 & 16 & 11,3 & 6,6 & 17,7 \\
\hline Gobernaciones & 9 & 13,6 & 6,4 & 24,3 & 7 & 9,2 & 3,8 & 18,1 & 16 & 11,3 & 6,6 & 17,7 \\
\hline Viajeros & 8 & 12,1 & 5,4 & & 6 & 7,9 & 3,0 & 16,4 & 14 & 9,9 & 5,5 & 16,0 \\
\hline $\begin{array}{l}\text { Viceministerio de Salud } \\
\text { Aeropuertos y/o Puertos y/o }\end{array}$ & 6 & 9,1 & $\begin{array}{l}3,4 \\
3,4\end{array}$ & 18,4 & 6 & 7,9 & 3,0 & 16,4 & 12 & 8,5 & 4,4 & 14,3 \\
\hline $\begin{array}{l}\text { Migraciones } \\
\text { Sector del Turismo (SENATUR, }\end{array}$ & 4 & 6,1 & 1,7 & 14,8 & 3 & 4,0 & 0,8 & 11,1 & 7 & 4,9 & 2,0 & 9,9 \\
\hline Agencias de viajes) & 5 & 7,6 & 2,5 & & 2 & 2,6 & 0,3 & 9,2 & 7 & 4,9 & 2,0 & 9,9 \\
\hline Sanatorios Privados & 1 & 1,5 & 0,1 & 8,2 & 5 & 6,6 & 2,2 & 14,5 & 6 & 4,2 & 1,6 & 9,0 \\
\hline $\begin{array}{l}\text { Dirección General de Promoción } \\
\text { de la Salud } \\
\text { Dirección General de }\end{array}$ & 5 & 7,6 & 2,5 & 16,8 & 1 & 1,3 & 0,1 & 7,1 & 6 & 4,2 & 1,6 & 9,0 \\
\hline $\begin{array}{ll}\text { Dirección } & \text { General } \\
\text { Comunicación en Salud } & \end{array}$ & 6 & 9,1 & 3,4 & 18,4 & 0 & 0,0 & 0,0 & 0,0 & 6 & 4,2 & 1,6 & 9,0 \\
\hline Sociedades científicas & 4 & 6,1 & 1,7 & & 1 & 1,3 & 0,1 & 7,1 & 5 & 3,5 & 1,2 & 8,0 \\
\hline Instituto de Previsión Social & 2 & 3,0 & 0,4 & 10,5 & 3 & 4,0 & 0,8 & 11,1 & 5 & 3,5 & 1,2 & 8,0 \\
\hline $\begin{array}{l}\text { Ministerio de Hacienda } \\
\text { Centro Europeo de Control }\end{array}$ & 2 & 3,0 & 0,4 & 10,5 & 0 & 0,0 & 0,0 & 0,0 & 2 & 1,4 & $\begin{array}{l}1,2 \\
0,2\end{array}$ & $\begin{array}{l}5,0 \\
5,0\end{array}$ \\
\hline Enfermedades & 0 & 0,0 & 0,0 & 0,0 & 1 & 1,3 & 0,1 & 7,1 & 1 & 0,7 & 0,0 & 3,8 \\
\hline
\end{tabular}

Se encontró que la mención de la ciudadanía estaba significativamente asociada a los temas de "medidas de prevención ambiental y control vectorial" (OR 11,4; Cl95\%=4,8-27,2; $p<0,001$ ).

\section{Evaluación de capacitación a periodistas}

El 11 de julio de 2014 se realizó un primer taller de capacitación en Comunicación de Riesgo dirigido a periodistas del sector privado, en el marco del plan de contingencia frente al Chikungunya. 
El resultado del taller de capacitación se evaluó a través del análisis de subtemas incluidos en las publicaciones de medios públicos y privados antes y después del taller de capacitación.

No se identificó una diferencia significativa en los temas sobre prevención incluidos en las noticias después de las capacitaciones. Tabla 6.

Tabla 6. Temas incluidos en las publicaciones, antes y después del taller de capacitación. Sector privado.

\begin{tabular}{|c|c|c|c|c|c|}
\hline \multirow[b]{2}{*}{$\begin{array}{l}\text { Total de temas incluidos en el } \\
\text { sector PRIVADO }\end{array}$} & \multicolumn{2}{|c|}{$\begin{array}{l}\text { Antes } \\
\mathrm{N}=42\end{array}$} & \multicolumn{2}{|c|}{$\begin{array}{l}\text { Después } \\
N=34\end{array}$} & \multirow[b]{2}{*}{$p$} \\
\hline & $\mathrm{n}$ & $\%$ & $\mathrm{n}$ & $\%$ & \\
\hline Plan - protocolos* & 24 & 57,1 & 7 & 20,6 & $0,002^{*}$ \\
\hline Mosquito - Criaderos & 18 & 42,9 & 16 & 47,1 & 0,89 \\
\hline $\begin{array}{l}\text { Número de casos - Anuncio de } \\
\text { caso }\end{array}$ & 26 & 61,9 & 16 & 47,1 & 0,19 \\
\hline Síntomas & 24 & 57,1 & 13 & 37,1 & 0,16 \\
\hline Medidas de prevención ambiental & 12 & 28,6 & 16 & 45,7 & 0,16 \\
\hline Autorreporte y/o consulta médica & 6 & 14,6 & 8 & 23,5 & 0,53 \\
\hline Medidas de protección persona & 6 & 14,3 & 8 & 23,5 & 0,53 \\
\hline Alerta & 10 & 23,8 & 9 & 25,7 & 0,89 \\
\hline Capacitación & 0 & 0 & 4 & 11,8 & 0,08 \\
\hline Diagnostico & 15 & 35,7 & 8 & 23,5 & 0,36 \\
\hline Antecedentes de viaje & 17 & 40 & 11 & 32,3 & 0,62 \\
\hline Similitud con el dengue* & 24 & 57,1 & 3 & 8,8 & $<0,001^{*}$ \\
\hline Historia de la enfermedad & 5 & 11,9 & 2 & 5,9 & 0,61 \\
\hline Links y teléfonos & 3 & 7,1 & 0 & 0 & 0,34 \\
\hline Origen de la palabra & 10 & 23,8 & 2 & 5,9 & 0,07 \\
\hline Ubicación de los casos & 19 & 45,2 & 14 & 41,2 & 0,9 \\
\hline Intersectorialidad & 5 & 11,9 & 9 & 26,5 & 0,18 \\
\hline Susceptibilidad y riesgo & 18 & 42,9 & 7 & 20,6 & 0,07 \\
\hline
\end{tabular}

\section{Análisis temporal de las publicaciones}

Se analizó el contenido de los artículos de prensa escrita según "momentos". Se definieron estos momentos, en función al análisis de la curva de frecuencia (Figura 1), como aquellos periodos donde se verifica un cambio (aumenta o se suspende) el número de publicaciones. El inicio de cada momento se definió como aquel donde comienzan las publicaciones (independiente del contenido de la misma) y su final, por el día en que paran. Se incluyó en el periodo a aquella publicación aislada de unos días antes o unos días después, si su tema central coincidía con los temas predominantes del período. Se contrastaron estos "momentos" con hitos relevantes desde una óptica noticiosa que explicaran la aparición o reducción del número de publicaciones.

Fueron identificados 6 hitos relevantes, según se detallan en la Figura 1. 
Figura 1. Total de publicaciones sobre chikungunya en medio de prensa escrita, por fecha de publicación. Paraguay Junio a octubre de 2014.

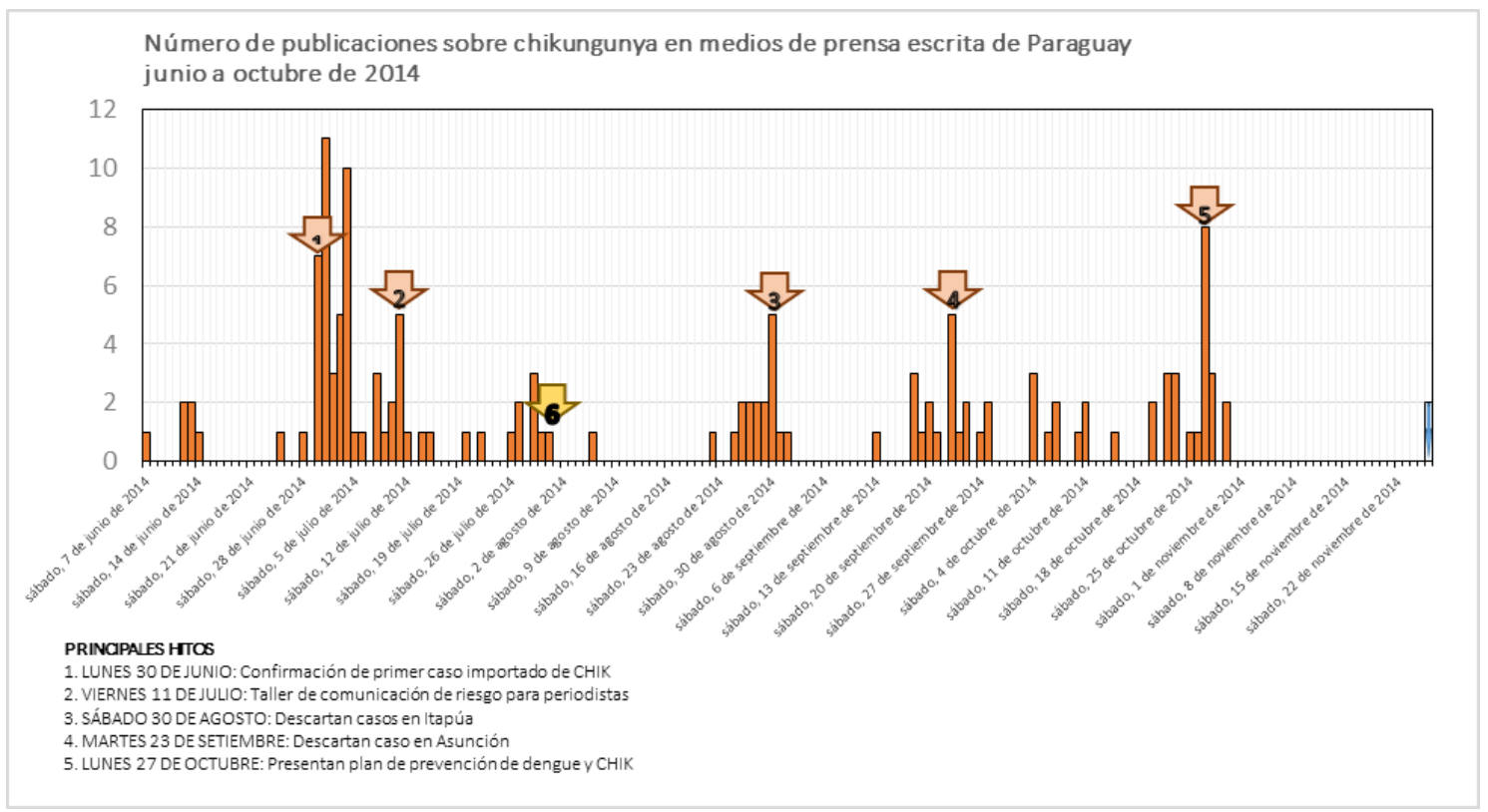

Como se observa en la Figura 2, los momentos 2, 3, 5 y 6 coinciden con el anuncio de casos sospechosos y/o confirmados. Como se detalló previamente, el "anuncio de nuevos casos" es el tema principal más frecuente en medios de comunicación privados. El momento 4, la reducción del número de publicaciones coincide con la aparición del Ébola como hecho noticioso, a raíz de la declaración por parte de la Organización Mundial de la Salud de Emergencia de Salud Pública de Importancia Internacional (ESPII) por la epidemia en África Occidental.

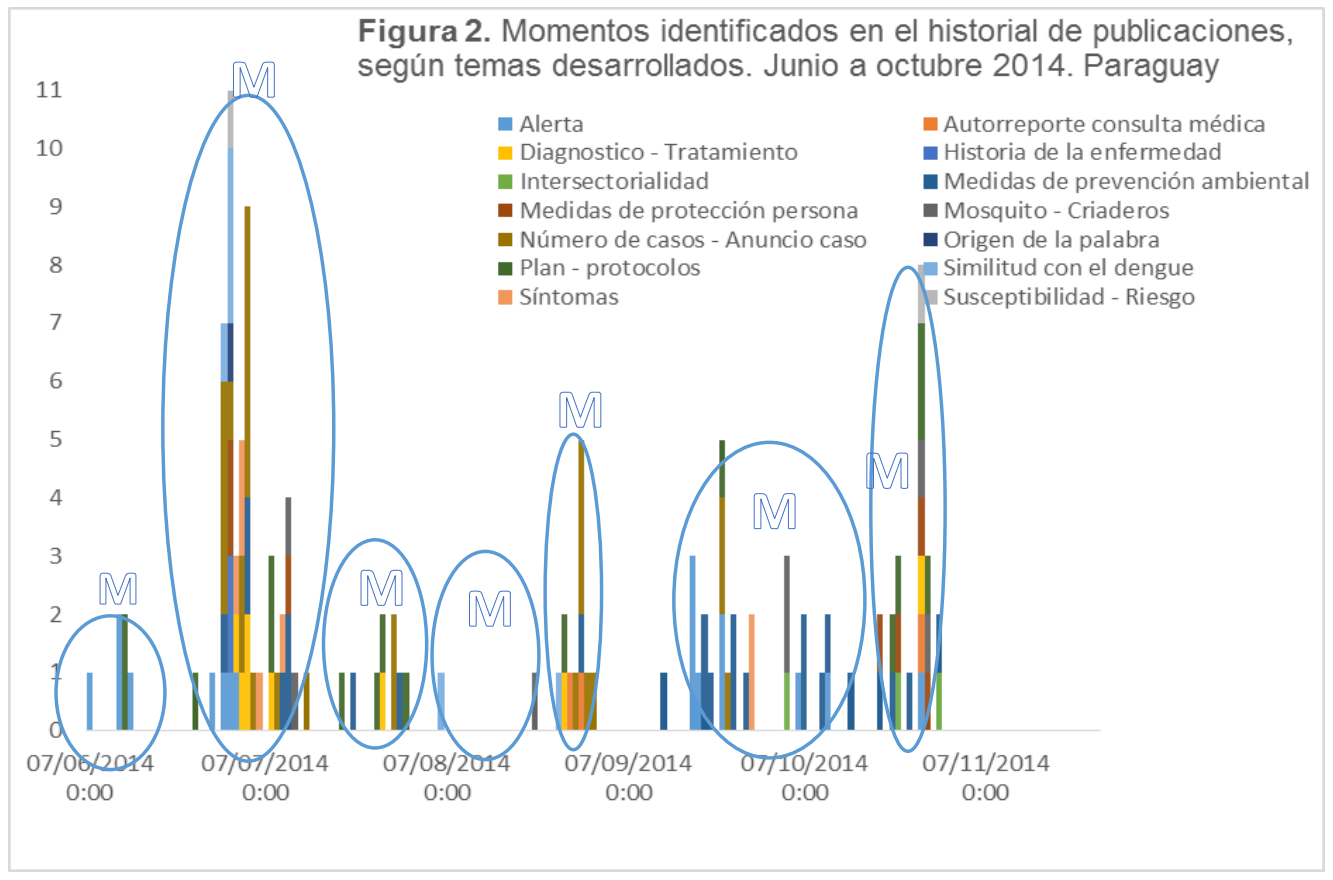




\section{Descripción de temas según momentos}

El "Momento 1", va de la semana del 7 de junio al 14 de junio, donde desde el Ministerio de Salud se hace el llamado de atención sobre la posibilidad de ingreso del virus de Chikungunya al país. Se publicaron 6 noticias en los medios, que abordaron dos temas centrales: "alerta" y "planificación". Figura 3.

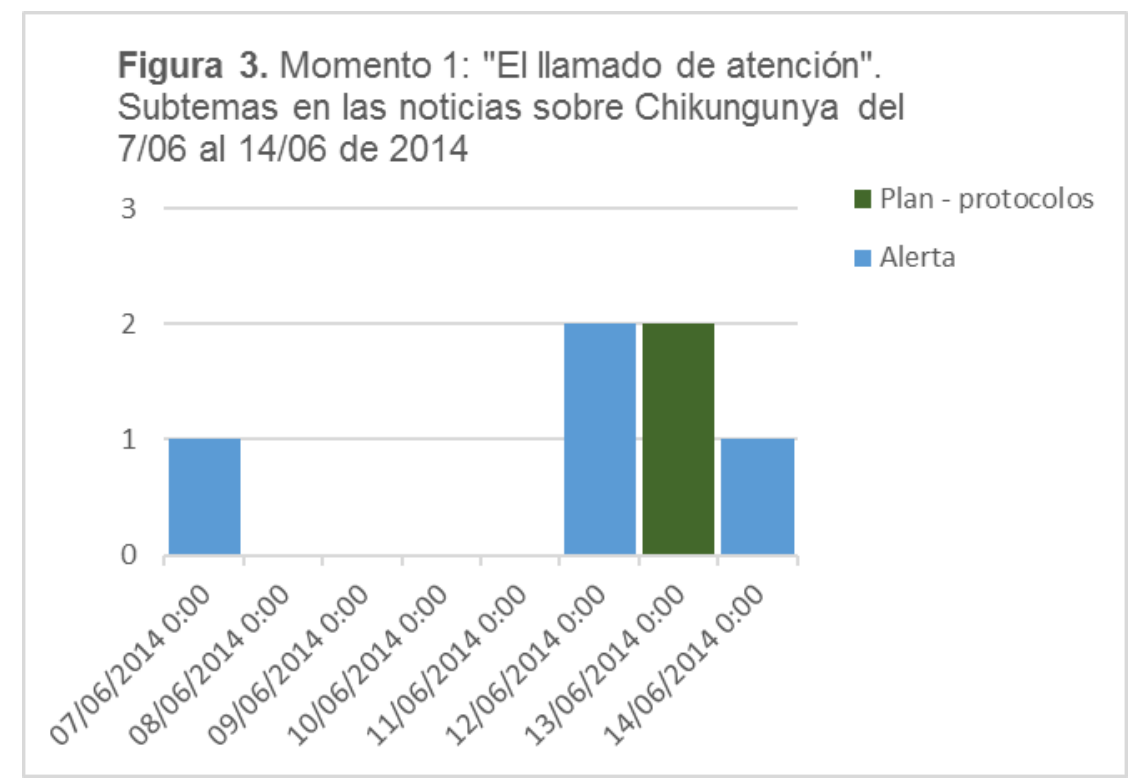

El "Momento 2", va del 25 de junio al 11 de julio. En este período se confirma oficialmente un primer caso importado. Se publicaron 51 noticias en los medios. Se abordaron 13 diferentes temas, lo que se explica por tratarse de una enfermedad nueva para el país. El principal tema fue el "anuncio del nuevo caso", pero además se nota información para dar a conocer la enfermedad, incluyendo información sobre: "síntomas", "medidas de control ambiental", "historia de la enfermedad", "tratamiento", "similitud con el dengue", "origen de la palabra", información sobre diagnóstico y tratamiento". Se menciona también la preocupación por la "susceptibilidad de la población" y la existencia de "criaderos" Al igual que en momento anterior, se insiste sobre la "alerta" y "planificación". La capacitación con periodistas que es objeto de análisis en este estudio se realizó el 11 de julio. Figura 4. 


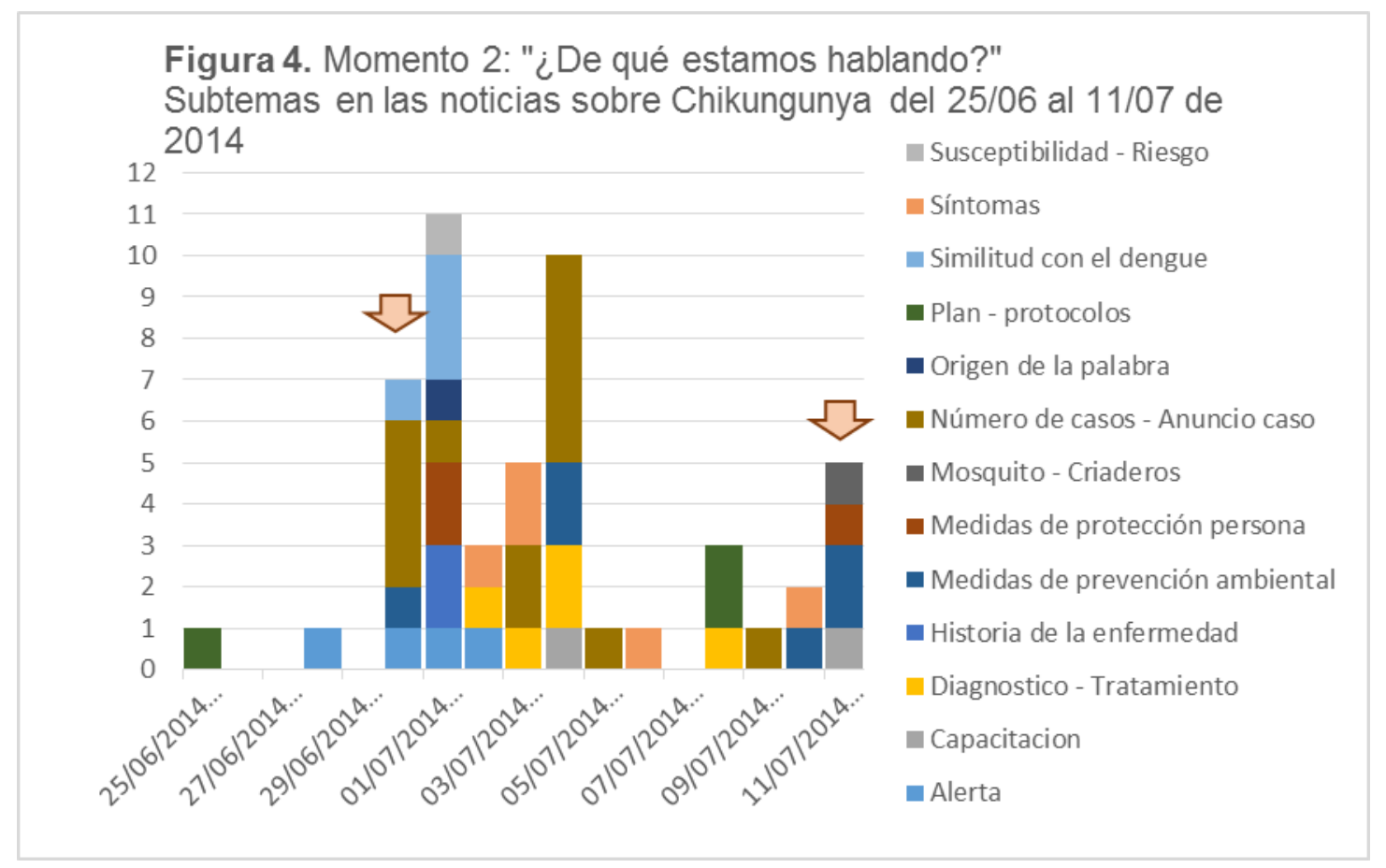

El "Momento 3", va del 20 al 31 de julio. En este periodo las noticias se concentran en cinco temas: "planificación", "reporte de casos sospechosos", "técnicas de diagnóstico", "capacitación" y "medidas de prevención del tipo ambiental". Se publicaron en total 10 noticias. Figura 5.

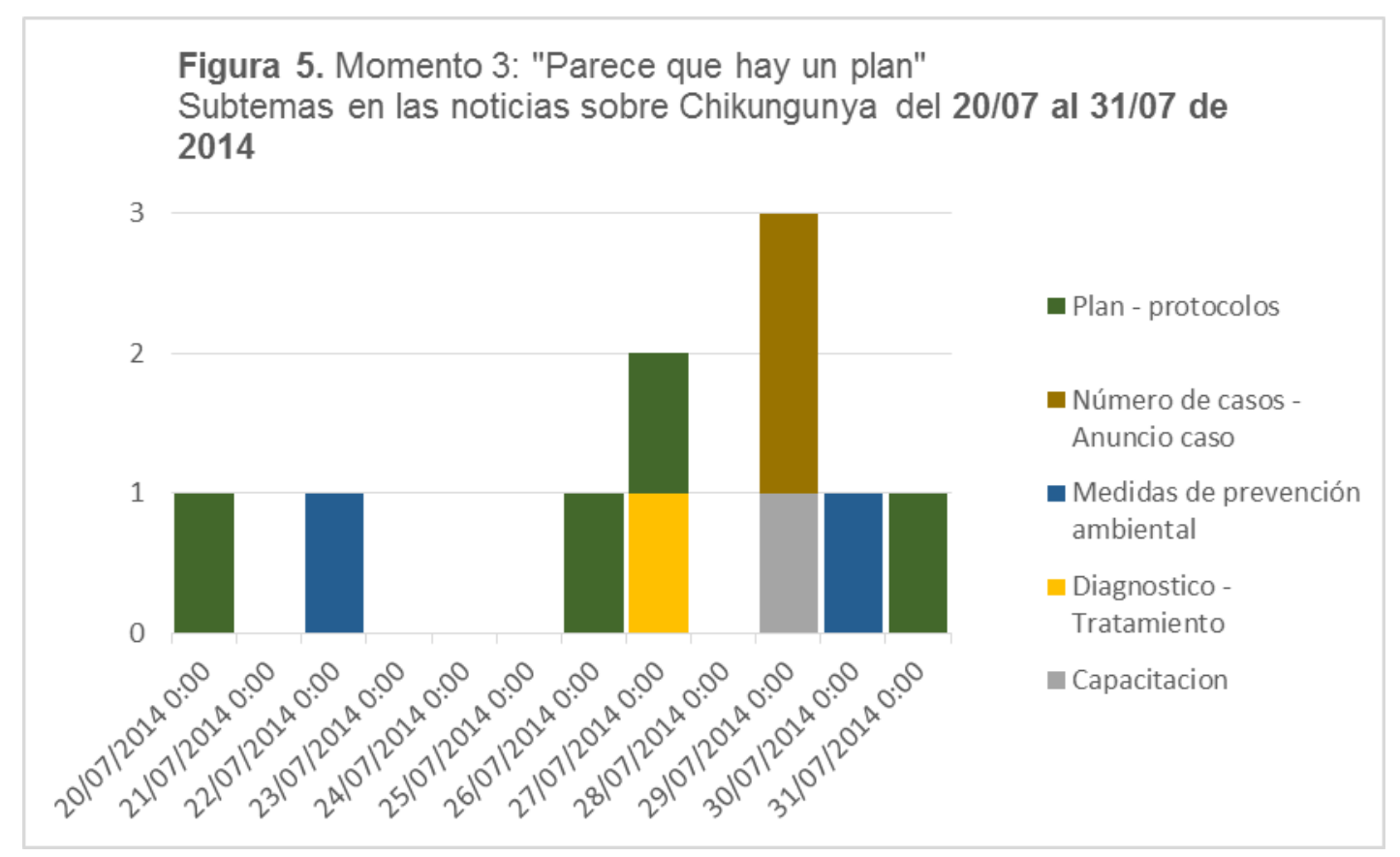

El "Efecto Ébola" se evidencia en el "Momento 4". Durante un periodo de casi tres semanas que van del 4 al 22 de agosto se publicaron apenas 2 noticias. 
Los temas abordados fueron la presencia de criaderos y la similitud entre el Chikungunya y el dengue. En este periodo el foco de la atención periodística estuvo centrado sobre la nueva amenaza a nivel mundial, con menos atención en el riesgo que seguía representando el Chikungunya para la región. Figura 6.

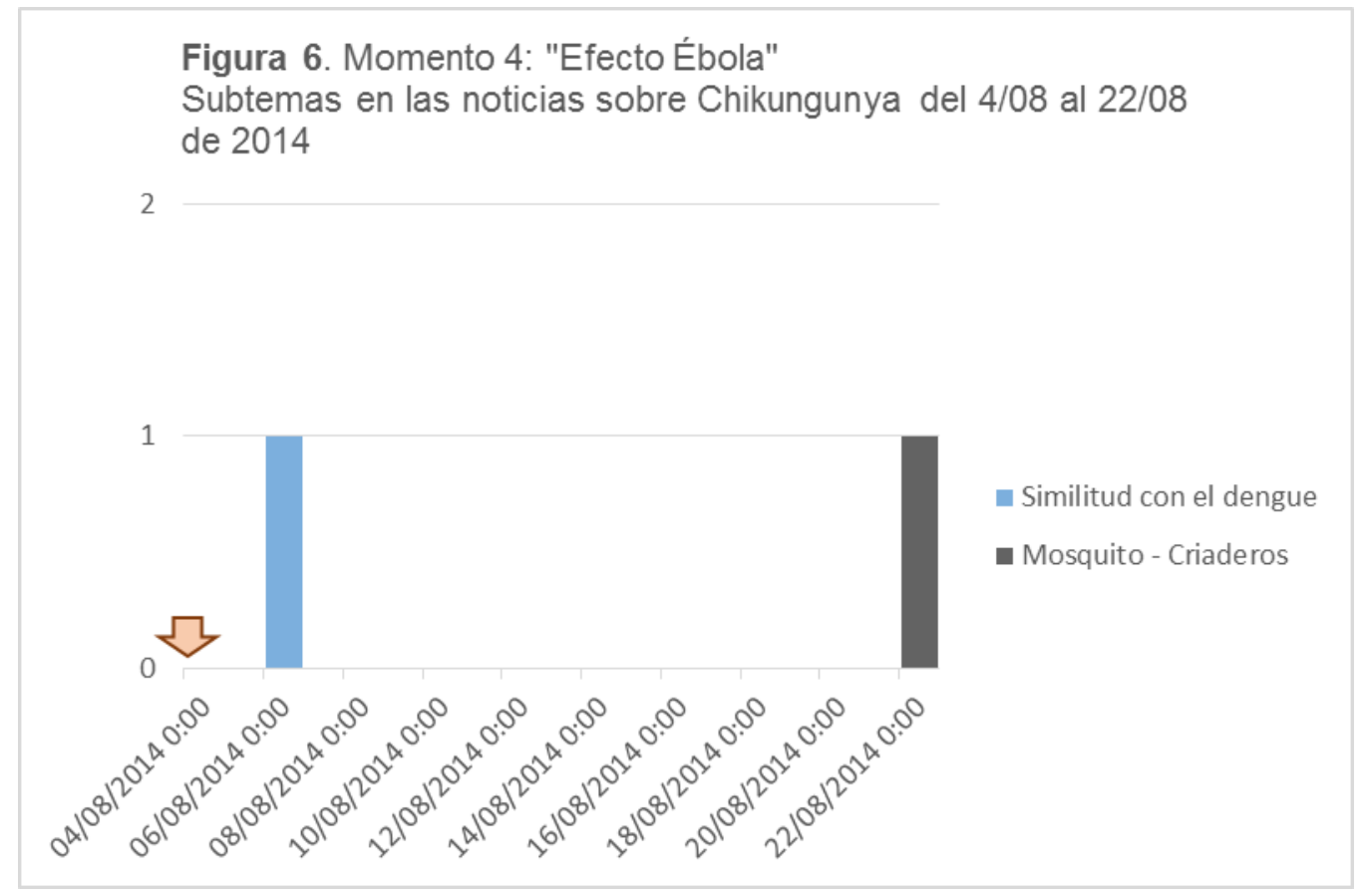

En el "Momento 5", el tema del Chikungunya se retoma en los medios de comunicación con publicaciones sobre capacitaciones dirigidas al personal de salud. En los medios de prensa del sector privado se hace mención a supuestos casos sospechosos, que son descartados. En este periodo otros temas tratados son: "similitud con el dengue", "medidas de control ambiental", "diagnóstico y tratamiento" y la importancia del "autorreporte". Este período va del 25 de agosto al 1 de setiembre, durante el que se publicaron 16 noticias. Figura 7.

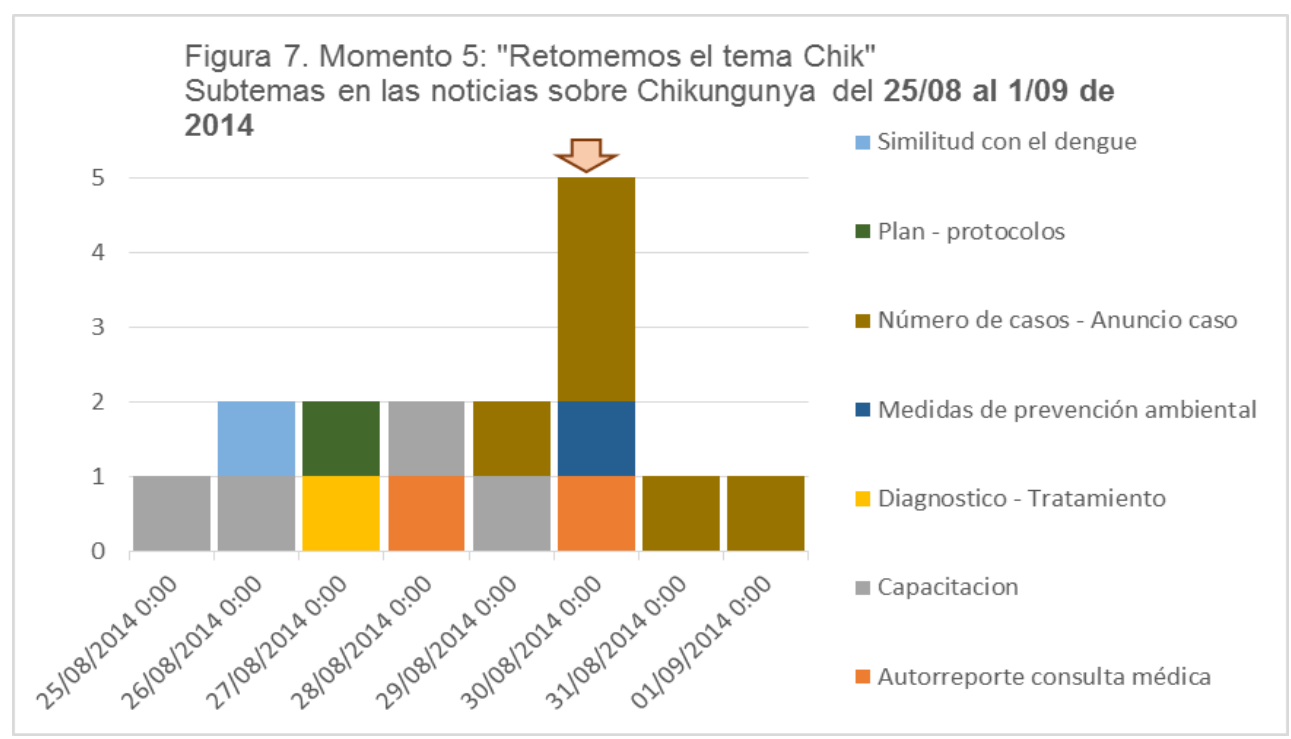


En el "Momento 6" se hace mayor énfasis al problema vectorial y las medidas de prevención en el ámbito ambiental relacionadas con la eliminación de criaderos. Este periodo va del 18 de setiembre al 15 de octubre e incluye el análisis de 28 publicaciones. Figura 8.

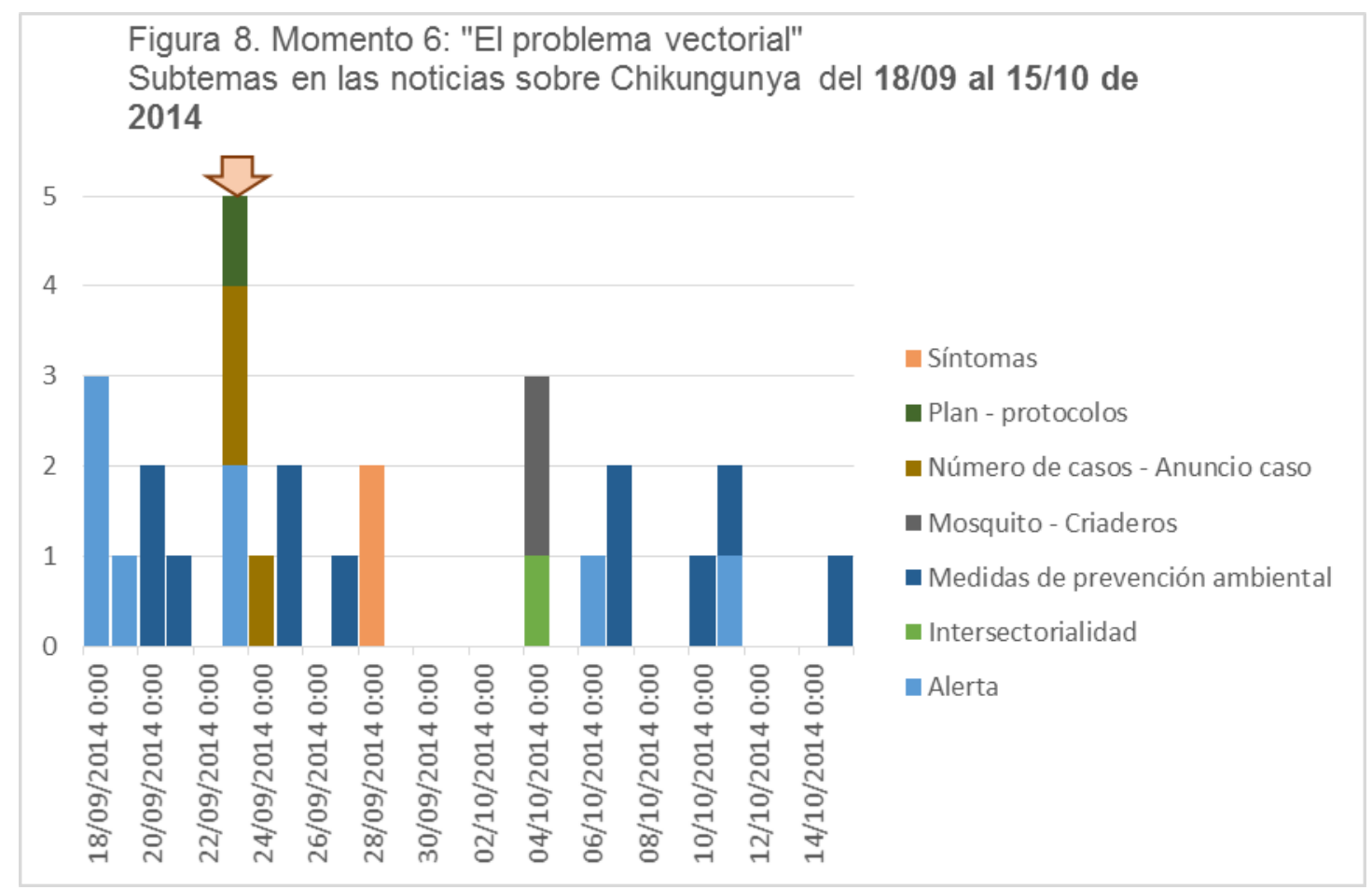

En el "Momento 7", del 22 al 10 de octubre, se publicaron 23 noticias, con diez tipos de subtemas abordados. Coincide con la presentación del plan de prevención de dengue y Chikungunya, donde en un único día se publicaron 8 informaciones, con 7 diferentes subtemas abordados: susceptibilidad, plan, proliferación de criaderos, medidas de protección personal, diagnóstico y tratamiento, importancia del autorreporte y alerta. En el mismo período se hicieron además menciones al trabajo intersectorial, capacitaciones brindadas sobre el tema y recomendaciones sobre las medidas de prevención vectorial. Figura 6. 
Figura 6. Momento 7: "Hay mucho que decir". Subtemas

incluidos en las publicaciones sobre Chikungunya del 22/10 al

$30 / 10$ de 2014

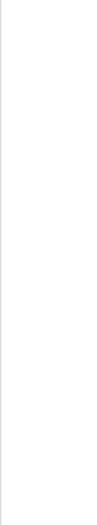

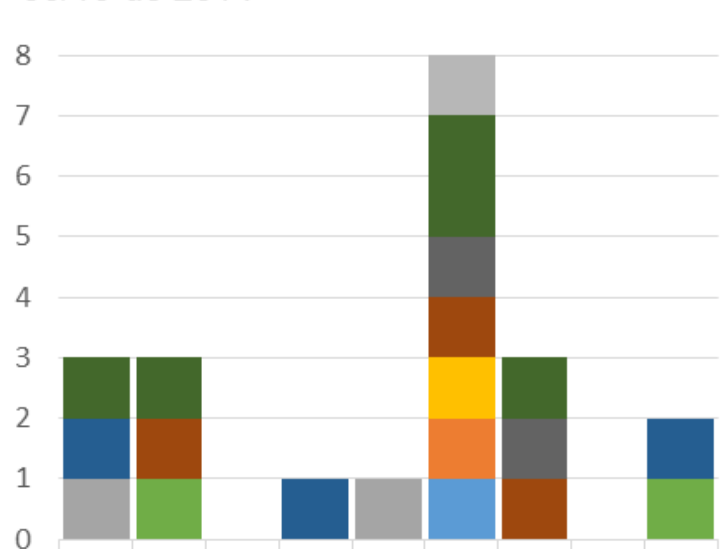

e.
- Susceptibilidad - Riesgo

- Plan - protocolos

- Mosquito - Criaderos

- Medidas de protección persona

- Medidas de prevención

ambiental

- Intersectorialidad

Diagnostico - Tratamiento

Capacitacion

- Autorreporte consulta médica

- Alerta

\section{Efecto "rebote"}

Del total de 76 informaciones publicadas en medios de prensa del sector privado, $18(18,4 \%)$ reprodujeron la información del sector público de manera textual y $21(27,6 \%)$ utilizaron datos o partes del texto de la información pública para la información que publicaron ese mismo día o al día siguiente.

En la Figura 7 se observa el número de publicaciones emitidas por parte del vocero oficial (Ministerio de Salud Pública) y la forma en que esta información fue replicada en los medios, ya sea a través de la transcripción textual o la utilización de los datos, al que denominamos "efecto rebote".

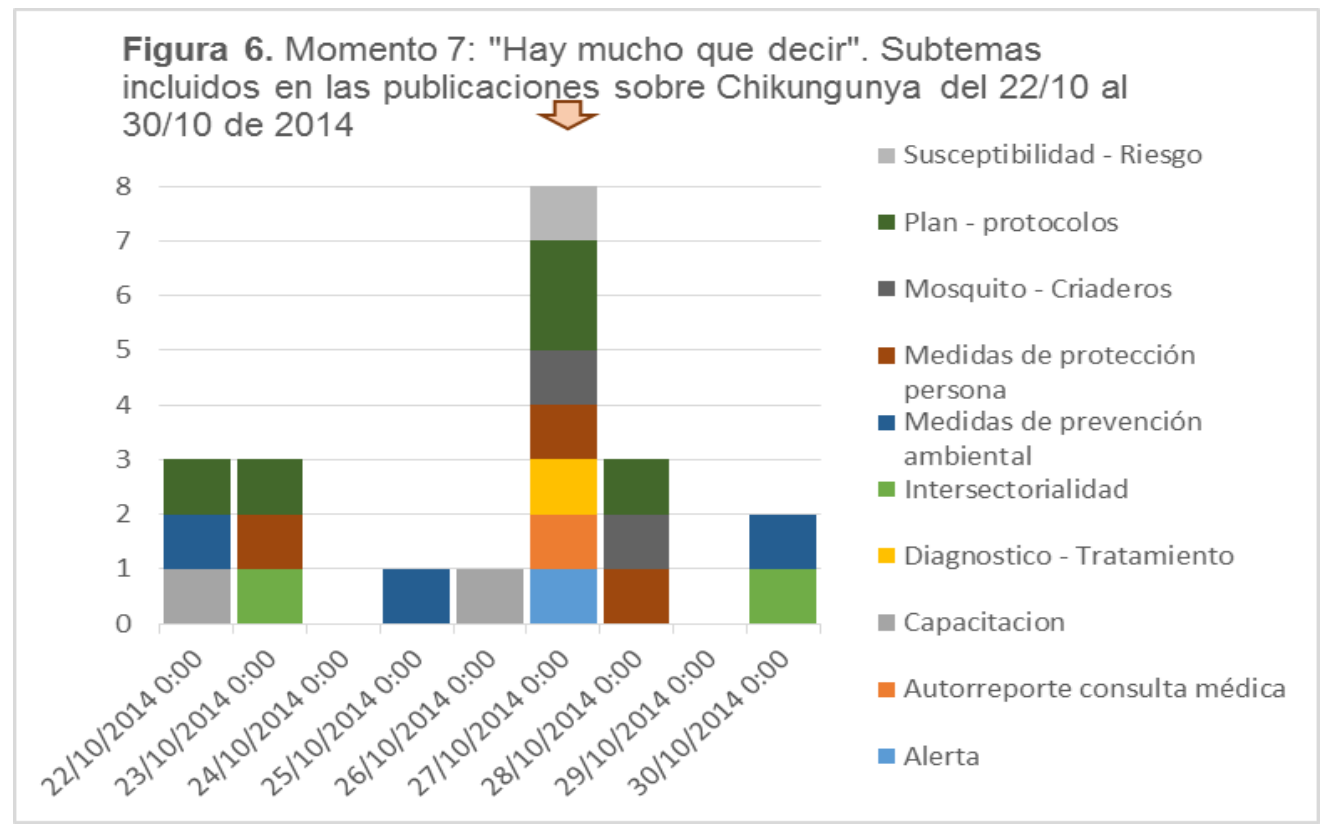


En general, de 52 publicaciones sobre el Chikungunya producidas por el Ministerio de Salud durante el periodo analizado, se tuvo una replicación en 34 publicaciones de medios de prensa escrito, lo que da una razón de uso de la información oficial como fuente primaria de la prensa de 0,7 . Los temas que tuvieron más difusión en los medios utilizando de base el informe de prensa oficial fueron las noticias sobre "Número de casos - Anuncio caso" (razón=2,6), las "Alertas" (razón=2,3) y las informaciones sobre "Medidas de protección personal" (razón $=1,5$ ). Los temas con más baja replicabilidad en los medios de prensa fue la información sobre "Plan y/o protocolos" (se produjeron 12 materiales oficiales con el tema central del plan, que fueron replicados en 2 informaciones de prensa) y las publicaciones de "Medidas de prevención ambiental" (se publicaron 11 noticias oficiales, que fueron replicadas en 2 noticias de medios del sector privados, razón=0,2).

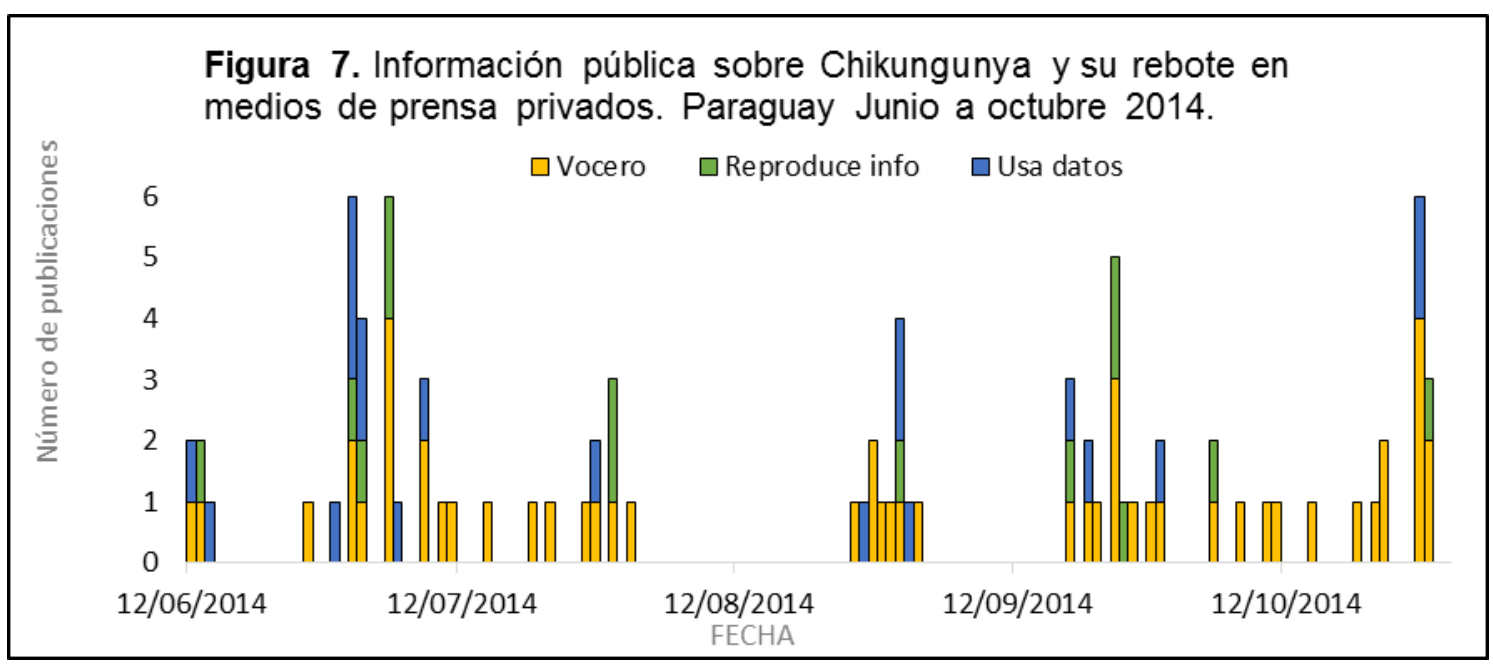

Tabla 7. Razón de uso de la información oficial por parte de los medios de prensa privados, según tema principal.

\begin{tabular}{cccc}
\hline Tema principal & $\begin{array}{c}\text { Gacetilla } \\
\text { oficial }\end{array}$ & $\begin{array}{c}\text { Noticias en medio privado } \\
\text { que reproduce o usa la } \\
\text { gacetilla oficial }\end{array}$ & $\begin{array}{c}\text { Razón de uso de la } \\
\text { información oficial }\end{array}$ \\
\hline Plan y/o protocolos & 12 & 2 & 0,2 \\
Medidas de prevención & 11 & 2 & 0,2 \\
ambiental & 9 & 1 & 0,1 \\
Capacitación & 5 & 13 & 2,6 \\
Número de casos & 4 & 7 & 0,5 \\
Anuncio caso & 3 & 1 & 2,3 \\
Diagnostico - Tratamiento & 4 & 3 & 0,5 \\
Alerta & 2 & 1 & 1,5 \\
Autorreporte & 2 & 1 & 0,5 \\
Medidas de protección & 2 & 1 & 1 \\
personal & 1 & $\mathbf{3 4}$ & 1 \\
Mosquito - Criaderos & 1 & & $\mathbf{0 , 7}$ \\
Similitud con el dengue & $\mathbf{5 2}$ & & \\
Síntomas & & &
\end{tabular}




\section{Discusión}

El riesgo de introducción del virus del Chikungunya (CHIKV) en Paraguay hizo necesario el diseño y puesta en marcha de un plan de Comunicación de Riesgo parar orientar las acciones relacionadas con la provisión de información y comunicación tanto para actores internos como externos, en las fases de preparación, introducción y rehabilitación que responden a un eventual brote epidémico.

El documento se orientó en las Nomas de Comunicación de Brotes Epidémicos de la OMS (OMS, 2005) y la Estrategia de Comunicación de Riesgo promovida por OPS (Brennan y Gutierrez, 2011), que plantea cinco principios básicos que deben estar presentes y ser transmitidos en el marco de un plan: Confianza, Transparencia, Anuncio Temprano, Diálogo con el público y Planificación.

La meta primordial para la comunicación de brotes epidémicos es comunicarse con el público de tal forma que mantenga o recupere la confianza (OMS, 2005). En este caso se considera a los medios de comunicación, como un público externo particular, ya que a su vez tiene la posibilidad de diseminar la información al resto del público externo. El hecho de que un $46 \%$ de las noticias de prensa reprodujeron total o parcialmente información proveída por el Ministerio de Salud, puede ser asociado con una muestra de confianza hacia el vocero oficial.

En el primer anuncio oficial del brote se establecen los parámetros de la confianza. El primer anuncio sobre nuevos casos de Chikungunya vino por parte del Ministerio de Salud. En los tres casos identificados en el período donde la prensa se adelantó e hizo mención a posibles casos sospechosos antes que la prensa oficial, estos casos fueron finalmente descartados.

El mantenimiento de la confianza del público durante todo el brote requiere transparencia (es decir, comunicación que sea veraz se comprenda fácilmente, sea completa y se atenga exactamente a los hechos) y mantener un diálogo con el público. La comunidad fue el tercer actor citado con mayor frecuencia en las publicaciones.

Asimismo, se evidenció que un 51,4\% (IC95 =42,9-59,9) hacían alguna mención al plan o protocolos de contingencia y que 11,3\% (IC95\%=6,6-17,7\%) lo tuvo como tema central. Esto demuestra que se cumplió con el principio de planificación.

Plantea la OMS que la comunicación de riesgos es más eficaz cuando se integra con el análisis y la gestión de riesgos (OMS, 2005).

Es importante entender la diferencia entre riesgo y percepción de riesgo. En epidemiología se define el riesgo es la probabilidad de un evento (Gordis, 2014). En el manejo integral del riesgo, se considera al riesgo como la relación entre la gravedad de la amenaza y la vulnerabilidad de la población expuesta (Planton, 2013). A su vez, la vulnerabilidad es definida como la predisposición a verse afectados de manera adversa por un evento (Planton, 2013). Se trata por tanto de una medida objetiva.

En tanto, la percepción de riesgo, es una construcción social que está determinada por el juicio subjetivo que la gente hace sobre las características y 
la gravedad de una amenaza. El factor de indignación social, potenciada por la percepción de falta de respuesta de las autoridades a cargo, aumenta los niveles de percepción de riesgo (Sandman, 2003).

La comunicación de riesgo debe realizar el análisis de público objetivo de los mensajes para lo cual necesariamente necesita evaluar la percepción de riesgo que se tiene del evento de manera a definir la orientación que deben tener los mensajes.

Se observa en los diferentes momentos de las publicaciones analizadas, que efectivamente existió un cambio en la orientación de los mensajes. En un primer momento se dio presencia a los mensajes relacionados con la alerta (que permiten aumentar la percepción de riesgo de la gente) mientras que en momentos subsiguientes se hizo mayor énfasis a la planificación y la promoción de medidas de prevención.

La metodología de análisis utilizada permitió identificar estos momentos y los mensajes generados. Permitió identificar cuáles son los temas preferidos por los medios de comunicación públicos y privados, y la manera cómo influyen unos en otros.

El estudio presenta limitaciones. No permitió evaluar el resultado del plan de comunicación, ya que no se identificaron cambios significativos en los temas abordados. El número de casos analizados antes del taller resultó escaso, lo que podría influir en la no significación estadística. Una debilidad del análisis es que compara dos situaciones en las que otros factores externos también varían (aparición de nuevos casos, informe sobre otras enfermedades), y no considera un grupo de comparación que pueda servir como contrafactual hipotético que permita evaluar lo que hubiera ocurrido con las publicaciones sin la capacitación realizada a los periodistas. En eventos sociales, de índole nacional, como es el ámbito de los medios de prensa, este grupo de comparación es difícil de construir. Tampoco se evalúan los factores que intervienen en la construcción de la noticia al interior de los medios de comunicación.

Se evidenció que existen ciertos temas que "atraen" a la prensa, mientras que otros, a pesar de su insistencia en las publicaciones oficiales, no siempre son replicados en los medios de comunicación. Se podría profundizar sobre cuales los factores que hacen que un mensaje de la vocería pública sea replicado en los medios privados, para potenciar este efecto "rebote".

El presente estudio no considera el efecto de las redes sociales en la diseminación del mensaje, ya que solo contabiliza las publicaciones en medios tradicionales en sus versiones impresas y digitales, pero no la difusión de los mismos a través de medios alternativos, tales como Facebook, twitter, WhatsApp y otras redes sociales.

Sería interesante realizar una investigación sobre cómo se maximiza el alcance de las publicaciones, al ser replicadas en estos medios. 


\section{Conclusión}

Se concluye que de acuerdo al análisis de las publicaciones oficiales y en medios de prensa privados sobre la contingencia frente al Chikungunya entre los meses de junio a octubre se han tenido presente los principios estándares de comunicación de riesgo. Las publicaciones oficiales han insistido con mensajes de prevención y planificación, temas que no siempre han sido divulgados textualmente en los medios de prensa, pero sí han permitido mantener un aceptable grado de confianza, reflejado en la razón de replicabilidad general de la información oficial.

\section{Referencias}

Brennan B. y Gutierrez V (2011). Guía para elaborar la estrategia de comunicación de riesgos. Washington, DC: OPS/OMS.

Gordis, L. (2014). Epidemiology. Philadelphia: Saunders.

Ministerio de Salud Pública y Bienestar Social de Paraguay (MSPBS) (2014).

Plan Nacional ante el Riesgo de Introducción de Chikungunya en Paraguay.

Disponible en:

http://www.vigisalud.gov.py/images/documentos/chikungunya/Plan EVChik 20

14 26.06.14.pdf. Accedido el 5 de noviembre de 2014, 10:44.

Organización Mundial de la Salud (OMS). (2005). Normas de comunicación de brotes epidémicos de la OMS. Suiza, Disponible en:

http://www.who.int/csr/resources/publications/WHO CDS 2005 28spweb.pdf

Organización Panamericana de la Salud (OPS). (2014). Número de casos reportados de chikungunya en países o territorios de las Américas 2013-2014 (por semanas). Semana Epidemiológica / SE 44 (actualizada al 31 de octubre del 2014). Disponible en:

http://www.paho.org/hq/index.php?option=com docman\&task=doc download\&l temid=270\&gid=27999\&lang=es. Accedido el 5 de noviembre de 2014, 10:44.

Planton, S. (Ed.) (2013). Annex III: Glossary. En Stocker, T.F., D. Qin, G.-K. Plattner, M. Tignor, S.K. Allen, J. Boschung, A. Nauels, Y. Xia, V. Bex and P.M. Midgley (Ed.). Climate Change: The Physical Science Basis. Contribution of Working Group I to the Fifth Assessment Report of the Intergovernmental Panel on Climate Change. Cambridge and New York. Cambridge University Press.

Sandman, P. (2003). The Four Kinds of Risk Communication. The Synergist, April, 26-27. 


\section{Anexo: Cuestionario utilizado para la carga de información}

\section{Información sobre Chikungunya publicada en medios escritos de Paraguay junio a octubre 2014}

ID

Fecha de publicación

Medio de publicación

Ministerio de Salud

OIP

Ua Nación

OHOY

U Ultima Hors

$\mathrm{ABC}$
Tipo de publicación

público Privado

Contenido

Reproduce textualmente informacion oficial

Usa datos de la información oficial

\begin{tabular}{|ll|} 
Incluye los siguientes temas: & \\
$\square$ Alerta & $\square$ Sintomas \\
$\square$ Mosquitos - criaderos & $\square$ Prevención ambiental \\
$\square$ Susceptibilidad - riesgo & $\square$ Protección personal \\
$\square$ Número de casos - Anuncio caso & $\square$ Intersectorialidad \\
$\square$ Ubicación de los casos & $\square$ Plan - protocolos \\
$\square$ Origen de la palabra & $\square$ Links telefonos \\
$\square$ Historia de la enfermedad & $\square$ Autorreporte consulta \\
$\square$ Similitud con el dengue & $\square$ Antecedente de viaje \\
$\square$ Diagnostico - Tratamiento & $\square$ Capacitación \\
\hline
\end{tabular}

\section{Tema principal}

Alerta

Mosquito-Criaderos

Susceptibilidad - Riesgo

Número de casos - Anuncio caso

Ubicación de los casos

Origen de la palabra

Historia de la enfermedad

Similitud con el dengue

Sintomas

Medidas de prevención ambiental

Medidas de protección persona

Intersectorialidad

Plan - protocolos

Capacitacion

Autorreporte consulta médica

Diagnostico - Tratamiento

\begin{tabular}{|lll|}
\hline Actores & & \\
\hline Ministerio de Salud & & \\
$\square$ Viceministerio de Salud & $\square$ SENEPA & $\square$ Municipalidad \\
$\square$ Dirección de Vigilancia de la Salud & $\square$ Sociedades científicas & $\square$ Turismo \\
$\square$ Dirección de Comunicación en Salud & $\square$ Comunidad - población & $\square$ Aeropuertos - Puertos - Migraciones \\
$\square$ Servicios de Salud - USF & $\square$ Medios de Comunicación & $\square$ Ministerio de Hacienda \\
$\square$ Dirección de Promoción de la Salud & $\square$ Viajeros & $\square$ Sanatorio privado \\
$\square$ Laboratorio Central & $\square$ Centro Europeo Control Enfermedades
\end{tabular}

